\title{
Prevention of Catastrophic Volcanic Eruptions, Large Earthquakes underneath Big Cities, and Giant Earthquakes at Subduction Zones
}

\author{
Yoshiaki Fujii ${ }^{1, *(\mathbb{D})}$, Morteza Sheshpari ${ }^{2}{ }^{\mathbb{D}}$, Jun-ichi Kodama ${ }^{1}$, Daisuke Fukuda ${ }^{1}$ \\ and Anjula BN Dassanayake ${ }^{3}$ \\ 1 Division of Sustainable Resources Engineering, Hokkaido University, Sapporo 060-8628, Japan; \\ kodama@eng.hokudai.ac.jp (J.-i.K.); d-fukuda@frontier.hokudai.ac.jp (D.F.) \\ 2 Department of Geotechnical Engineering, University of Ottawa, Ottawa, ON K1N 6N5, Canada; \\ mshes064@uottawa.ca \\ 3 Department of Earth Resources Engineering, University of Moratuwa, Moratuwa 10400, Sri Lanka; \\ abndassanayake@gmail.com \\ * Correspondence: fujii6299@frontier.hokudai.ac.jp; Tel.: +81-11-706-6299
}

Received: 13 May 2018; Accepted: 4 June 2018; Published: 7 June 2018

\begin{abstract}
Catastrophic volcanic eruptions, large earthquakes beneath big cities, or giant earthquakes at subduction zones are apparently the biggest problems facing the sustainability of human society. However, imminent prediction methods for these events have never been established, except that volcanic eruptions can only be predicted by exceptional efforts by dedicated researchers. Even if a prediction method has been established, the method cannot significantly reduce infrastructure damage, although it could slightly reduce the number of fatalities. On the other hand, prevention of eruptions or earthquakes could significantly reduce, not only the number of fatalities, but also infrastructure damage. Therefore, the authors propose (1) gradual energy release by supercritical power generation to prevent catastrophic eruptions; (2) gradual seismic energy release by injecting water into seismic sources to prevent large earthquakes beneath big cities; and (3) exploding existing nuclear warheads underground to prevent giant earthquakes at subduction zones. Necessary technical developments, costs, risks, and problems will also be explained.
\end{abstract}

Keywords: prevention; catastrophic volcanic eruptions; large earthquakes underneath big cities; giant earthquakes at subduction zones

\section{Introduction}

Catastrophic volcanic eruptions, large earthquakes beneath big cities, or giant earthquakes at subduction zones are apparently the biggest problems facing the sustainability of human society. However, imminent prediction methods for these events have not been established so far, except that volcanic eruptions can be predicted only by exceptional efforts by dedicated researchers. For example, the eruption of Mt. Usu, Japan in 2000 [1,2] was predicted by Professor Hiromu Okada at Hokkaido University, Japan. Even if a prediction method has been established, the method may not significantly reduce infrastructure damage. Deliberate considerations of the management of natural disaster risk [3] based on precise predictions may contribute to further decrease economic losses. However, predictions could slightly reduce the number of fatalities. On the other hand, prevention of eruptions or earthquakes, which has never been attempted, if developed, could significantly reduce, not only the number of fatalities, but also infrastructure damage. This paper considers how to prevent these devastating disasters and tries to clarify necessary technical developments, costs, risks, 
and problems. Euro and Japanese yen are converted at rates of $1 \mathrm{EUR}=1.2 \mathrm{USD}$ and $1 \mathrm{JPY}=0.0091 \mathrm{USD}$ when necessary.

\section{Prevention of Catastrophic Volcanic Eruptions}

The Yellowstone supervolcano, for example, erupted ca. 2.1 Ma (million years ago) with $2450 \mathrm{~km}^{3}$ ejecta, and 1.3 Ma and 0.63 Ma with $1000 \mathrm{~km}^{3}$ ejecta [4]. The log-normal distribution is a distribution function that can be used to represent eruption intervals [5]. The data are not enough but the average interval and standard deviation are calculated as $10^{5.856 \pm 0.0544}$ years, assuming the log-normal distribution. Let us assume that the next catastrophic eruption occurs $10^{5.856 \pm 0.0544}$ years after the previous eruption, and calculate the probability of eruption after now. Cumulative distribution $\Phi$ at $x$ for the log-normal distribution with the average value $\mu$ and standard deviation $\sigma$ can be represented as:

$$
\Phi=\frac{1}{2}\left(1+\operatorname{erf} \frac{\ln x-\mu}{\sqrt{2 \sigma^{2}}}\right)
$$

where erf is the error function (Figure 1). The probability $p$ at $t_{1}$ that a catastrophic eruption occurs before $t_{2}$ can be calculated as:

$$
p=\frac{\Phi\left(t_{2}\right)-\Phi\left(t_{1}\right)}{1-\Phi\left(t_{1}\right)}
$$

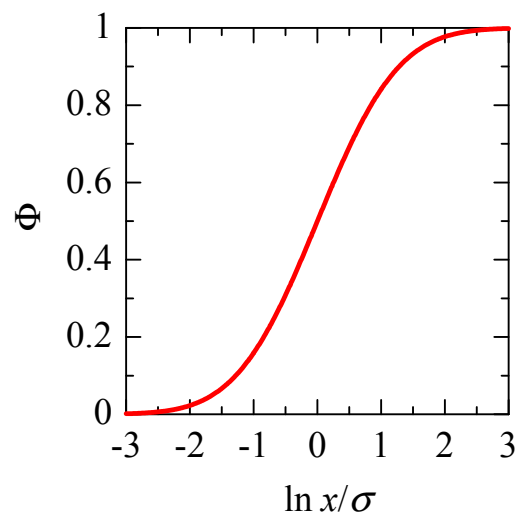

Figure 1. Cumulative distribution for the normal distribution with the average of 0 and standard deviation of $\sigma$.

The probability for an imminent eruption is not zero and it reaches almost $100 \%$ in several hundred thousand years (Figure 2).

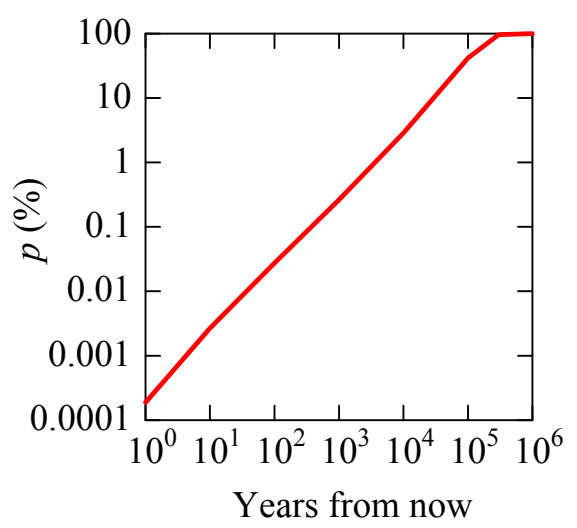

Figure 2. Probability of a catastrophic eruption at Yellowstone supervolcano. 
If Yellowstone erupts, volcanic ash will distribute vastly [6] and $90 \%$ of people within $1000 \mathrm{~km}$ of the volcano will die due to suffocation. In addition, the air temperature in the Northern Hemisphere will drop by $10 \mathrm{~K}$ for several to tens of years due to the sulfate aerosols from the volcano, which will obstruct sunlight from reaching the ground surface [7]. No crops can be raised and most people will starve to death. In short, people in the Northern Hemisphere will certainly be made extinct in several hundred thousand years if we do nothing. Civilization may remain because people in the Southern Hemisphere could survive and move to the Northern Hemisphere. However, let us propose to prevent such catastrophic eruptions by gradually relieving energy for eruptions using a supercritical geothermal system $[8,9]$.

The supercritical geothermal system makes drill holes in the vicinity of a magma chamber. Heat is exchanged at the borehole end and power is generated at the surface. Problems in this system are corrosion of drilling rods and durability of drilling bits due to the high temperature and low $\mathrm{pH}$ near magma chambers. These matters can be solved using a silica carbide composite [10] and an electro pulse drilling technique [11].

The eruption energy of Krakatoa in 1883 was estimated to be 200 MT (Megaton TNT (trinitrotoluene) equivalent) [12], namely $840 \times 10^{15}(\mathrm{~J})$. The volcanic explosivity index (VEI) is defined as:

$$
\mathrm{VEI}=\log \left(V_{\mathrm{E}}\right)-4
$$

where $V_{\mathrm{E}}$ is the volume of the ejecta [13]. VEI of Krakatoa (1883) is estimated to be 6 [14]. Assuming that the eruption energy is proportional to ejecta volume, VEI can be converted to eruption energy $E_{R}(J)$ by

$$
E_{\mathrm{R}}=840 \times 10^{\mathrm{VEI}+9}
$$

The VEI of Yellowstone eruptions for the eruptions of 2.1 Ma, 1.3 Ma, and 0.63 Ma, are estimated to be 8.4, unknown, and 8.0, respectively. Dividing the eruption energy by the average interval of $0.735 \mathrm{My}$ (million years), the average power can be calculated as 8.9 MW and 3.6 MW for the first and the third known eruptions, respectively. Adopting a safe side estimation, it can be said that only $10 \mathrm{MW}$ of supercritical power generation is enough to prevent the catastrophic eruptions of Yellowstone. The output of a moderate scale nuclear power plant is $1 \mathrm{GW}$; several GW are expected for supercritical power plants. A $10 \mathrm{MW}$ power plant is much smaller than those power plants and no serious technical problems related to output scale are predicted.

The most cost consuming part is drilling in the geothermal power plants. For example, the magma chamber of the Yellowstone supervolcano is ca. $8 \mathrm{~km}$ deep and drilling costs are expected to be too expensive. However, the cost of the electro pulse drilling is $800,000 \mathrm{EUR}$ based on $100 \mathrm{EUR} / \mathrm{m}$ [11]. Assuming that a drilling hole can be used for 30 years, the drilling cost is just $0.0041 \mathrm{EUR} / \mathrm{kWh}$ $(0.0049 \mathrm{USD} / \mathrm{kWh})$. This is cheap enough and the power plant can be profitable even after considering other various costs. Therefore, there would be no problems with respect to costs.

On the other hand, humans in the Northern Hemisphere will be made extinct if a catastrophic eruption occurs at Yellowstone. The economic loss would be almost equal to the world GDP (Gross Domestic Product, 74 trillion USD in 2015) at the eruption year. Assuming that the world economy would gradually recover to the previous level in the following 100 years, total economic losses would be $74 \times 100 / 2=3700$ trillion USD. Dividing the total economic losses by the average eruption interval, the annual economic loss would be ca. 5 billion USD/y.

Drilling unexpectedly encountered magma in the Iceland Deep Drilling Project and supercritical power generation was carried out [8] without any hazards. However, there would still be risks that those drillings stimulate volcanoes and induce unpredicted catastrophic eruptions. This issue should be, of course, deliberately investigated before the method is adopted in practice. 


\section{Prevention of Large Earthquakes beneath Big Cities}

Twenty-two $M \geq 6$ earthquakes occurred beneath big cities between 2000 and 2016, for example, in Japan, excluding aftershocks [15], which induced severe human and property damages. In Kumamoto in 2016 (M6.5), for example, 110 people died, 184,643 buildings, including the Kumamoto Castle, collapsed, and the economic losses were 2.4-4.6 trillion JPY (22-42 billion USD [16]). In Tottori in 2016 (M6.6) in Japan, as another example, 30 people died, 14,748 buildings collapsed, and the agricultural damage was 1.6 billion JPY (15 million USD [17]).

Gradual release of seismic energy by injecting water through a drill hole to the seismic fault is proposed to prevent such large earthquakes. An M6 is occurs at an average interval of 100 years in Kumamoto. One thousand M4 earthquakes (an M4 causes almost no damage in Kumamoto) in 100 years will release the seismic energy for an M6 based on the following relationship between seismic energy $E_{\mathrm{S}}(\mathrm{J})$ and magnitude $M$ :

$$
\log E_{S}=4.8+1.5 M
$$

Namely, $10 M 4$ for one year or ca. one $M 4$ for a month will prevent $M 6$ earthquakes.

Fujii et al. (2014) evaluated the amount of water injection $V\left(\mathrm{~m}^{3}\right)$ and the maximum magnitude $M_{\max }$ of the induced seismicity based on cases of geothermal systems (EGS), water injection to seismic faults, and so on, as follows [18]:

$$
M_{\text {max }}=0.75 \log V-0.48
$$

Namely, $9.4 \times 10^{5} \mathrm{~m}^{3}$ water should be injected to induce an $M 4$. This amount of water can be injected, for example, for a week at $1.5 \mathrm{~m}^{3} / \mathrm{s}$. The scheduled injections would be carried out very carefully under a dense microseismic and seismic monitoring to ensure safety.

Focal depth of typical large earthquakes under big cities are $23 \mathrm{~km}$ for Tokyo (1923), $24 \mathrm{~km}$ for Nankai (1946), 16 km for Hyogo (1995), 12 km for Kumamoto (2016), 11 km for Tottori (2016) [15], and so forth. On the other hand, even the world's deepest drillings, such as $12.3 \mathrm{~km}$ at the Kola Superdeep Borehole (2011) or $9.1 \mathrm{~km}$ at the KTB (German Continental Deep Drilling Program (in German: Kontinentales Tiefbohrprogramm der Bundesrepublik Deutschland), 1994) are not enough. The problems are the same as the supercritical geothermal system, that is, high temperatures and corrosion, and would be solved by the silica carbide composite and electro pulse drilling.

The cost for $9.4 \times 10^{5} \mathrm{~m}^{3}$ water is 136 million JPY/year based on the water price for the public baths in Sapporo, Japan. The cost for 100 years is 13.6 billion JPY. The cost for $12 \mathrm{~km}$ of drilling would be 56 billion JPY based on a total cost of 42 billion JPY for KTB [19]. Assuming that the drill hole can be used for 100 years, the total cost becomes ca. 70 billion JPY (640 million USD). The cost is already much cheaper than the economic damage of 2.4-4.6 trillion JPY (22-42 billion USD). Moreover, gray-water can be prepared at a much cheaper price and the drilling costs would be as low as 1.2 million EUR (1.4 million USD) by adopting electro pulse drilling.

Equation (6) was obtained from various in-situ test results. However, there is still a possibility that an M6 is unexpectedly induced while water is being injected to induce an $M 4$. This risk can be minimized by gradual injection under careful monitoring. The injection can be cancelled when the released energy exceeds an M4. Further study will also be required to determine the best location of the injection on the seismic fault to induce small earthquakes.

\section{Prevention of Giant Earthquakes at Subduction Zones}

A Russian study claimed that there were no $M \geq 8.3$ earthquakes that occurred during the period in which underground nuclear tests were frequently carried out [20]. Unfortunately, the details of the study are not known because we did not succeed in accessing the original article. However, lists of the underground nuclear tests and giant earthquakes can be obtained from References [21,22], respectively. We examined the relationships between them by ourselves, expanding the lower limit to $M \geq 8$, and found that few giant earthquakes occurred during the period in which underground nuclear tests were frequently carried out (Figure 3). 


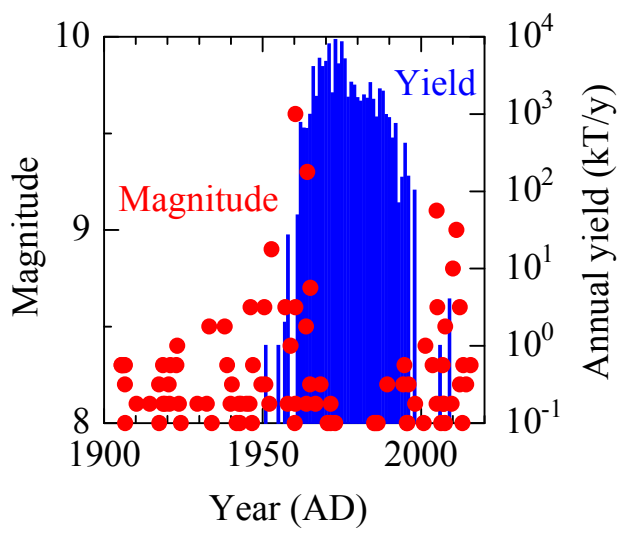

Figure 3. Magnitude of giant earthquakes and annual yield of underground nuclear tests from 1900 to 2016.

The probability of the null hypothesis, assuming that there was no Granger causality from annual yield or number of underground nuclear tests to annual seismic energy or number of giant earthquakes, was calculated with the statistical package software R [23]. Granger causality does not mean usual causality. For example, it can be said that there is Granger causality from time series A to time series B if $B$ can be predicted with $A$ better than only from the auto correlation of $B$. If the probability is less than 0.05 , the null hypothesis is rejected and it can be statistically said that the necessary condition of the existence of Granger causality from underground nuclear explosion to the occurrence of giant earthquakes is satisfied.

The probability values were more than 0.05 which means that the null hypothesis was not rejected although some of them were not so large (Table 1). Therefore, it can be statistically said that no Granger causality was found from underground nuclear tests to occurrences of the giant earthquakes. However, it is apparent that seismicity was restrained when the annual yield of the underground nuclear explosions was more than $1 \mathrm{MT} /$ year (Figure 4). The mechanism of the restraint should be investigated further in future, but it could be induced small earthquakes due to vibration from underground nuclear explosions thereby relieving the strain energy for giant earthquakes. Manga et al. (2012) explained that one of the causes of induction of smaller earthquakes in far fields by large earthquakes would be the change in permeability due to transient stress disturbances [24]. Electromagnetic waves from nuclear explosions could be another mechanism [25]. However, electromagnetic waves were also emitted by the atmospheric nuclear tests and the absence of giant earthquakes after the period of atmospheric nuclear tests cannot be explained.

Table 1. Probability of the null hypothesis.

\begin{tabular}{ccc}
\hline \multirow{2}{*}{ Underground Nuclear Explosions } & \multicolumn{2}{c}{ Giant Earthquakes } \\
\cline { 2 - 3 } & Annual Number & Annual Seismic Energy \\
\hline Annual number & 0.132 & 0.27 \\
Annual yield & 0.120 & 1.00 \\
\hline
\end{tabular}

Comparing the locations of nuclear tests and giant earthquakes from 1900 to 2016, nuclear tests and giant earthquakes are found in the same area for only Alaska. It is remarkable that five giant earthquakes occurred during the 70 years before the nuclear tests in Alaska but only a rather small one occurred during the 50 years after the tests (Figure 5). This also implies the prevention of giant earthquakes by underground nuclear explosions. 


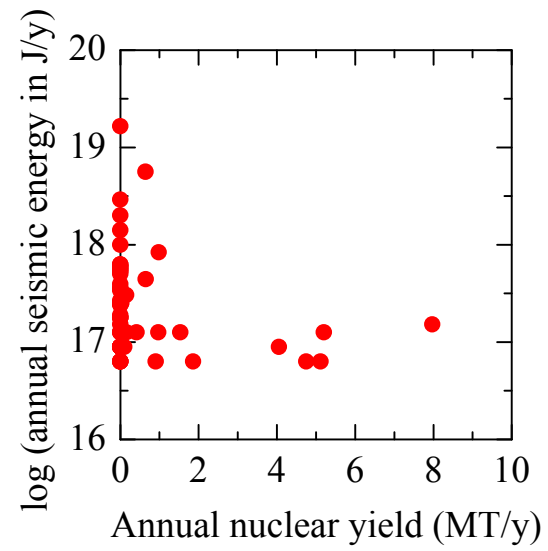

Figure 4. Relationship between annual nuclear yield and annual seismic energy from 1900 to 2016.

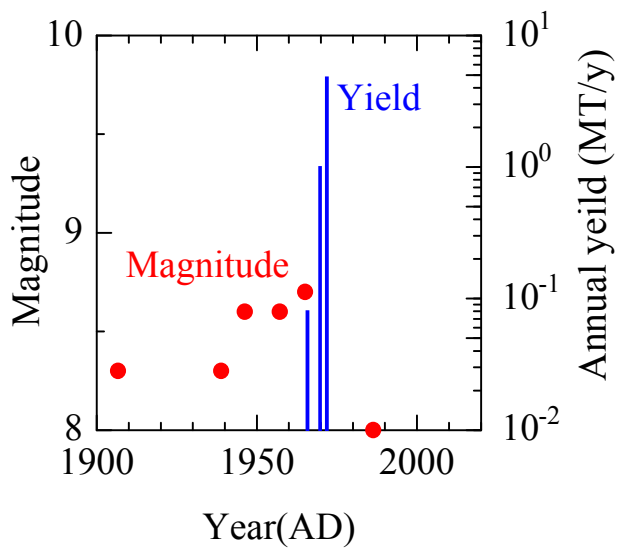

Figure 5. Annual yield of underground nuclear explosions and magnitude of giant earthquakes in Alaska.

Let us assume that the underground nuclear explosions prevented the occurrences of the giant earthquakes and propose to explode the existing nuclear warheads in the United States, Russia, the United Kingdom, and so forth, underground to prevent giant earthquakes. The total yield of the existing 25,900 warheads is $7000 \mathrm{MT}$ [21]. The minimum yield to prevent a giant earthquake is $1 \mathrm{MT} / \mathrm{y}$ as stated before. However, let us assume that $2 \mathrm{MT} / \mathrm{y}$ is used to ensure the reduction of giant earthquake occurrences. Therefore, the amount of the existing nuclear warheads is for 3500 years. Considering the deterioration of nuclear warheads, the existing warheads may be used for 100 years though.

The cost of the recent underground nuclear test by North Korea was estimated to be ca. 5 million USD/test by South Korea [26]. The cost of the proposed method, if the $2 \mathrm{MT} / \mathrm{y}$ is divided into 10 tests, can be very roughly estimated as 50 million USD/y. On the other hand, the property damage by the giant earthquakes listed in Wikipedia are 235 billion USD for Tohoku, Japan, in 2011, 86 billion USD for Sichuan, China, in 2008, and 15-30 billion USD for Chile in 2010, between 1906 and 2012 [27]. This means that the total property damage was at least 336 billion USD in 107 years or ca. 3 billion USD/y. The cost of the prevention is less than $1 / 60$ of the earthquake damage.

The relationship between underground nuclear tests and giant earthquakes was obtained based on actual observation. However, the biggest possible risk of the proposed method would be an unexpected induction of giant earthquakes instead of preventing them. Deliberate investigation should be made before the practice of the method, of course. The biggest problem of this method would be obtaining social consensus. 


\section{Concluding Remarks}

Catastrophic volcanic eruptions, large earthquakes beneath big cities, or giant earthquakes at subduction zones are apparently the biggest problems against the sustainability of human society. However, imminent prediction methods for them have never been established so far except that volcanic eruptions can only be predicted by exceptional efforts by dedicated researchers. Even if a prediction method was established, the method could not significantly reduce infrastructure damage, although it could slightly reduce the number of fatalities. On the other hand, prevention of eruptions or earthquakes could significantly reduce not only the number of fatalities but also infrastructure damage. Therefore, the authors propose to prevent those devastating disasters as follows.

Gradual energy release by supercritical power generation was proposed to prevent catastrophic eruptions. The necessary technical innovation is drilling into the depths. However, after the innovation, power generation itself would be profitable. The risk is unpredicted induction of unwanted catastrophic eruptions.

Gradual seismic energy release by injecting water into the seismic sources was proposed to prevent large earthquakes beneath big cities. The necessary technical innovation is the same as above. After the innovation, the costs would be much less than the average damage by earthquakes. The risk is unpredicted induction of unwanted large earthquakes.

Prevention of giant earthquakes at subduction zones by exploding the existing nuclear warheads underground was proposed. The cost is less than 1/60 of average giant earthquake damage. The risk is the possible unexpected induction of giant earthquakes. The biggest problem would be obtaining social consensus. However, it is worth to further consider this method because it would significantly contribute to world peace by not only preventing giant earthquakes but also by disarming the nuclear weapons.

The authors admit that the estimation on cost and risk in this study are very rough at this stage. More precise estimations should be done in further study.

Author Contributions: Conceptualization: Y.F. and M.S.; writing and original draft preparation: Y.F. and A.B.D.; writing, review, and editing: J.-i.K. and D.F.

Funding: This research received no external funding.

Acknowledgments: The authors thank Masato Yamada, an undergraduate student at Hokkaido University, for collecting data.

Conflicts of Interest: The authors declare no conflict of interest.

\section{References}

1. Jones, T.E. Evolving approaches to volcanic tourism crisis management: An investigation of long-term recovery models at Toya-Usu Geopark. J. Hosp. Tour. Manag. 2016, 28, 31-40. [CrossRef]

2. Yamagishi, H.; Watanabe, T.; Yamazaki, F. Sequence of faulting and deformation during the 2000 eruptions of the Usu volcano, Hokkaido Japan-Interpretation and image analyses of aerial photographs. Geomorphology 2004, 57, 353-365. [CrossRef]

3. Kesete, Y.; Peng, J.; Gao, Y.; Shan, X.; Davidson, R.A.; Nozick, L.K.; Kruse, J. Modeling insurer-homeowner interactions in managing natural disaster risk. Risk Anal. 2014, 34, 1040-1055. [CrossRef] [PubMed]

4. Yellowstone Caldera, Wikipedia. Available online: https://en.wikipedia.org/wiki/Yellowstone_Caldera (accessed on 13 May 2018).

5. Udagawa, S.; Imanaka, H.; Koyaguchi, T.; Takayasu, H. Statistical analysis of occurrence of eruptions at Sakurajima volcano. Proc. Volcanol. Soc. Jpn. 1999, 32. (In Japanese)

6. Mastin, L.G.; Eaton, A.R.; Lowenstern, J.B. Modeling ash fall distribution from a Yellowstone supereruption. Geochem. Geophys. Geosyst. 2014, 15, 3459-3475. [CrossRef]

7. The Epoch Times. Available online: http://www.epochtimes.jp/jp/2010/08/html/d23986.html (accessed on 13 May 2018). (In Japanese) 
8. Elders, W.A.; Friðleifsson, G.Ó.; Albertsson, A. Drilling into magma and the implications of the Iceland Deep Drilling Project (IDDP) for high-temperature geothermal systems worldwide. Geothermics 2014, 49, 111-118. [CrossRef]

9. Watanabe, N.; Numakura, T.; Sakaguchi, K.; Saishu, H.; Okamoto, A.; Ingerbritsen, S.E.; Tsuchiya, N. Potentially exploitable supercritical geothermal resources in the ductile crust. Nat. Geosci. 2017, 10, 140-144. [CrossRef]

10. Nakazato, N.; Kohyama, A.; Kohno, Y. Effects of pressure during preform densification on $\mathrm{SiC} / \mathrm{SiC}$ composites. Open J. Non-Metall. Mater. 2013, 3, 10-13. [CrossRef]

11. Schiegg, H.O.; Rodland, A.; Zhu, G.; Yuen, D.A. Electro-Pulse-Boring (EPB): Novel super-deep drilling technology for low cost electricity. J. Earth Sci. 2015, 26, 37-46. [CrossRef]

12. MacNeill, A.R. Dynamics of Dinosaurs and Other Extinct Giants; Columbia University Press: New York, NY, USA, 1989.

13. Glossary-VEI, Volcanic Hazards Program, USGS (United States Geological Survey) Web Site. Available online: https:/ / volcanoes.usgs.gov/vsc/glossary/vei.html (accessed on 29 May 2018).

14. Breining, G. The Deadlist Volcanoes. In Super Volcano: The Ticking Time Bomb Beneath Yellowstone National Park; Voyageur Press: Minneapolis, MN, USA, 2007.

15. Japan Meteorological Agency. Available online: http://www.data.jma.go.jp/svd/eqdb/data/shindo/index. php (accessed on 13 May 2018). (In Japanese)

16. Cabinet Office, Government of Japan. Available online: http://www.bousai.go.jp/updates/h280414jishin/ pdf/h280414jishin_35.pdf (accessed on 13 May 2018). (In Japanese)

17. Cabinet Office, Government of Japan. Available online: http://www.bousai.go.jp/updates/h281021jishin/ pdf/h281021jishin_09.pdf (accessed on 13 May 2018). (In Japanese)

18. Fujii, Y.; Takahashi, K.; Fukuda, D.; Kodama, J. Shale gas extraction and CCS may induce serious seismicity. In Proceedings of the Workshop on Rock Engineering and Environment at ARMS8 (2014 ISRM International Symposium -8th Asian Rock Mechanics Symposium), Sapporo, Japan, 14-16 October 2014; pp. 41-46.

19. The Japanese Assoc. Petr. Tech. Available online: https://www.japt.org/html/iinkai/drilling/seikabutu/ fukaboriiin/fukabori.html (accessed on 13 May 2018). (In Japanese)

20. Sputnik. Available online: https://jp.sputniknews.com/science/20150725634763/ (accessed on 13 May 2018). (In Japanese)

21. Nuclear Tests-Databases and Other Material, Johnston's Archive. Available online: http://www. johnstonsarchive.net/nuclear/tests/ (accessed on 13 May 2018). (In Japanese)

22. Search Earthquake Catalog, Earthquake Hazards Program, U.S. Geological Survey. Available online: http:/ / earthquake.usgs.gov/ earthquakes/search/ (accessed on 13 May 2018).

23. The R Project for Statistical Computing. Available online: https://www.r-project.org/ (accessed on 13 May 2018).

24. Manga, M.; Beresnev, I.; Brodsky, E.E.; Elkhoury, J.E.; Elsworth, D.; Ingebritsen, S.E.; Mays, D.C.; Wang, C.-Y. Changes in permeability caused by transient stresses: Field observations, experiments, and mechanisms. Rev. Geophys. 2012, 50, RG2004. [CrossRef]

25. Sheshpari, M. Magnotosphere anomaly, hexagonal crystal resonance and created consequences for triggering earthquakes. Electron. J. Geotech. Eng. 2016, 21, 4301-4304.

26. Sankei News. Available online: http://www.sankei.com/world/news/161005/wor1610050062-n1.html (accessed on 13 May 2018). (In Japanese)

27. Lists of Earthquakes, Wikipedia. Available online: https://en.wikipedia.org/wiki/Lists_of_earthquakes (accessed on 13 May 2018).

(C) 2018 by the authors. Licensee MDPI, Basel, Switzerland. This article is an open access article distributed under the terms and conditions of the Creative Commons Attribution (CC BY) license (http:/ / creativecommons.org/licenses/by/4.0/). 